\section{Long term survival in non-encapsulated primary liposarcoma of the mediastinum}

\author{
Ritu G Grewal, Kenneth Prager, \\ John H M Austin, Heidrun Rotterdam
}

\begin{abstract}
An elderly woman presented with dyspnoea secondary to extensive mediastinal invasion by a primary well differentiated liposarcoma of the mediastinum. Five years after partial resection and postoperative radiotherapy (45 Gy) she is alive and well. To our knowledge, long term survival has not previously been reported for a non-encapsulated mediastinal liposarcoma treated by incomplete resection and subsequent radiation therapy.
\end{abstract}

(Thorax 1993;48:1276-1277)

Primary liposarcomas are relatively uncommon neoplasms, occurring most commonly in the lower extremities and retroperitoneum. We are aware of only 60 patients with primary liposarcoma in the mediastinum. ${ }^{1-5}$ Only five of these patients, each with a well encapsulated tumour, have been reported as free of disease after surgical excision. ${ }^{35}$ Whenever possible, complete surgical exci-

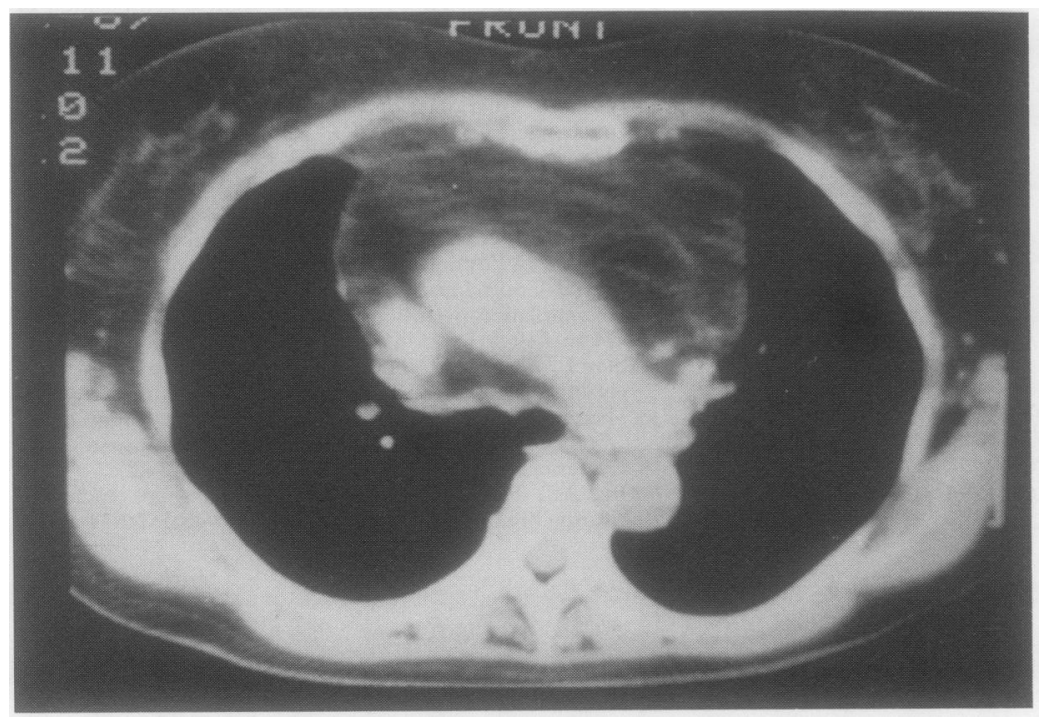

Figure 1 Anterior mediastinal mass in a 75 year old woman. Computed tomographic scan showing a broad mass of adipose attenuation laced throughout by ill defined strands of soft tissue attenuation. The mass displaces the ascending aorta posteriorly. sion is the recommended mode of treatment. ${ }^{235}$

We present a patient with a primary mediastinal liposarcoma which was characterised by extensive local invasion. Although only partial resection was possible, after postoperative radiotherapy the patient is alive and well five years later.

\section{Case report}

A 75 year old previously healthy woman presented in May 1987 with a 10 month history of gradually progressive dyspnoea on exertion. Respiratory rate was $22 /$ minute. Physical examination was otherwise normal, and there was no evidence of superior vena cava obstruction. The results of routine blood tests, electrocardiography, and barium swallow were normal. Chest radiography revealed a large anterior mediastinal mass mimicking a very large heart and also widening the superior mediastinum to the right of the trachea. Computed tomographic scanning (fig 1) showed the mass was of predominantly fatty attenuation. Arterial blood gas (room air) $\mathrm{pH}$ was $7 \cdot 42, \mathrm{PCO}_{2} 5 \cdot 2 \mathrm{kPa}$, and $\mathrm{PO}_{2} 8.4$ $\mathrm{kPa}$. Forced expired volume in one second $\left(\mathrm{FEV}_{1}\right)$ was 0.80 litres $(40 \%$ predicted $)$, forced vital capacity (FVC) was 0.83 litres (30\% predicted), and $\mathrm{FEV}_{1} / \mathrm{FVC}$ ratio was $96 \%$.

A median sternotomy and bilateral anterio thoracotomy were performed in July 1987. A large anterior mediastinal fatty tumour was found containing numerous hard foci, each measuring $1-3 \mathrm{~cm}$ in diameter. Gross invasion of the pericardium and left atrium was evident. The tumour encased the left phrenic nerve. Foci of invasion of the right lung, aortic arch, aortopulmonary window, and lef pulmonary artery were also present. Approximately one quarter of the total tumour mass $(450 \mathrm{~g})$ was resected from the anterior mediastinum. Additional resection was considered impossible because of invasion of adjacent structures. The extent of the mass appeared unchanged on postoperative chest radiographs.

On gross pathological examination the tumour was soft, fatty and contained ill defined regions of firmness. Microscopic examination revealed well differentiated liposarcoma. In many regions, large fat cells showed only minor variations in size and nuclear atypia. In other regions, lipoblasts with irregular hyperchromatic nuclei and cytoplasmic lipid droplets were seen (fig 2). Foci that felt firm on gross examination corresponded to areas of atypical spindle cells amidst fibrosis on histopathological examination. Special stains for mucin (mucicarmine, periodic acid schiff (PAS), and PAS with diastase) were negative. Immunoperoxidase stains for the epithelial markers cytokeratin and epithelial membrane antigen were negative. An S-100 stain was positive both in the 




Figure 2 Well differentiated liposarcoma. Atypical hyperchromatic nuclei are abundant. Rare lipoblasts (arrow) are seen (inset). Haemotoxylin and eosin. Magnification $\times 100$ (inset $\times 400$ ). identified easily by its low attenuation levels ( -70 to -130 Hounsfield units). ${ }^{8}$ On computed tomographic scanning attenuation of a liposarcoma varies from predominantly that of normal fat to soft tissue levels. ${ }^{7-9}$ The computed tomographic appearance correlates closely with the gross and microscopic anatomical findings. Poorly differentiated tumours, which tend to be quite cellular, have mean attenuation levels (15 to 25 Hounsfield units) approaching that of other solid tumours. ${ }^{78}$ Magnetic resonance imaging is also accurate in identifying fatty tumours; however, it is less anatomically precise than computed tomographic scanning. ${ }^{9}$

Liposarcomas are classified histologically into four main types: (1) well differentiated; (2) myxoid; (3) round cell; and (4) pleomorphic. ${ }^{13}$ For the lower extremities and retroperitoneum the five year survival for patients with well differentiated and myxoid liposarcomas is about $80 \%$, whereas for round cell and pleomorphic types it is around $20 \% .{ }^{4}$ For the mediastinum no long term survivor to our knowledge has had other than a well differentiated, encapsulated tumour. ${ }^{23}$

Radiotherapy has generally produced poor results in treating liposarcoma of the mediastinum compared with liposarcoma in other sites. ${ }^{36}$ Large doses of radiation (approximately $90 \mathrm{~Gy}$ ) are believed to be necessary to attain remission, but the risk of mediastinal fibrosis precludes giving such high doses to patients with mediastinal liposarcoma. ${ }^{356}$ The dose of radiation used in the mediastinum has been variable but is generally less than 60 Gy. ${ }^{35}$ We are unaware of any previous report of prolonged survival in a patient with mediastinal liposarcoma treated with radiation.

To our knowledge this is the first report of a documented long term survivor with a nonencapsulated, diffusely infiltrating mediastinal liposarcoma. We suggest that treatment with subtotal resection of the tumour ("debulking") followed by radiation therapy be considered for this entity. dyspnoea on exertion as her only complaint. The radiographic appearance of the mass remained unchanged.

\section{Discussion}

The spectrum of mediastinal liposarcoma varies from well differentiated and encapsulated to pleomorphic and non-encapsulated. The reported age range varies from nine months to 77 years, but most patients with this disease are over 40 years. ${ }^{235}$

Liposarcomas have been described in all mediastinal compartments, most commonly in the posterior mediastinum. ${ }^{7}$ These tumours can attain massive sizes and weigh as much as $7 \mathrm{~kg}^{3}$ Common presenting symptoms include chest pain, dyspnoea, wheezing, cough, and weight loss, but patients may be asymptomatic. ${ }^{35}$ Obstruction of the superior vena cava has been described in association with early mortality. ${ }^{3}$

The appearance of the chest computed tomographic scan may be diagnostic. Fat is normal in the mediastinum and can be
1 McLean TR, Almassi GH, Hackbarth DA, Janjan NA, Potish RA. Mediastinal involvement by myxoid liposar-

2 Dogan R, Ayrancioglu K, Aksu O. Primary mediastinal liposarcoma: a report of a case and review of the literature. Eur f Cardiothorac Surg 1989;3:367-70.

3 Schweitzer DI Aguam AS. Primary liposarcoma of the mediastinum: report of a case and review of the literature. F Thorac Cardiovasc Surg 1977;74:83-97.

4 Plukker JThM, Joosten HJM, Rensing JBM, Van Haelst UJGM. Primary liposarcoma of the mediastinum in a child. F Surg Oncol 1988;37:257-63.

5 Shibata K, Koga Y, Onitsuka T, Wake N, Ishii K, Sekiya $R$, et al. Primary liposarcoma of the mediastinum: a case report and review of the literature. Fap $f$ Surg 1986; 16:277-83.

6 Reitan JB, Kaalhaus O. Radiotherapy of liposarcomas. $\mathrm{Br}$ f Radiol 1980;53:969-75.

7 Mendez G, Isikoft MB, Isikoft SK, Sinner WN. Fatty tumors of the thorax demonstrated by CT. AFR 1979; 133:207-12.

8 Waligore MP, Stephens DH, Soule DH, McLeod RA. Lipomatous tumors of the abdominal cavity: CT appearance and pathologic correlation. $A \mathscr{F} R$ 1981;137: 539-45.

9 Dooms GC, Hricak H, Scolletto RA, Higgins CB. Lipomatous tumors and tumors with fatty component: MR imaging potential and comparison of MR and CT results. Radiology 1985;157:479-83. coma. Ann Thorac Surg 1989;47:920-1. 